\title{
How to Explain the Parents Cancer to their Children: A Specific Intervention to Enhance Communication Inside the Family
}

\author{
Gallina $F^{1}$, Mazza $\mathbf{U}^{1}$, Tagliabue $L^{1}$, Sala $F^{2}$, Ripamonti $\mathbf{C}^{2}$ and Jankovic $\mathbf{M}^{3^{*}}$ \\ ${ }^{1}$ Department of Mental Health, Clinical Psychology's Unit, San Gerardo Hospital, Monza, Italy \\ ${ }^{2}$ Department of Psychology, University of Milano-Bicocca, Italy
}

${ }^{3}$ Department of Hematology and Oncology, Pediatric Clinic, University of Milano-Bicocca, Foundation MBBM, San Gerardo Hospital, Monza, Italy

*Corresponding author: Momcilo Jankovic, Department of Hemato-Oncology, Pediatric Clinic, University of Milano-Bicocca, Foundation MBBM, San Gerardo Hospital, Pergolesi 33 Monza, Italy, Tel: 023271673; E-mail: m.jankovic@hsgerardo.org

Received date: November 12, 2015; Accepted date: December 29, 2015; Published date: February 27, 2016

Copyright: (c) 2016 Gallina, et al. This is an open-access article distributed under the terms of the Creative Commons Attribution License, which permits unrestricted use, distribution, and reproduction in any medium, provided the original author and source are credited.

\begin{abstract}
Objective: This article describes a multidisciplinary intervention dedicated to patients with cancer and with underage children. It is well known that children of severely ill parents can develop emotional and behavioral problems. Different studies underline the efficacy of an open communication with children about the parent's illness to reduce distress but also the difficulties of parents to explain it to their children. The intervention, realized at San Gerardo Hospital, aims to inform or improve the children's knowledge of their parent's cancer, and to open communication about cancer inside the family.

Methods: This intervention is characterized by the integration of a psychologist and a pediatric hematooncologist and by the direct involvement of children. After the fact-finding parents sessions, the pediatric hematooncologist and the psychologist meet children in specific settings, without parents present, to describe, with the support of images and metaphors, the parent's cancer and to understand children's needs or fears. In particular the pediatric hemato-oncologyst uses the flowered garden metaphor to explain to children the parent's illness and the treatments. Then the clinicians share the content of the previous sessions with parents. Counseling sessions to parents are also organized to increase the parental competence and the sharing of cancer-related concerns in the family. In addition, a specific questionnaire has been realized to evaluate children's psychological conditions after the intervention, family atmosphere and parents' satisfaction.
\end{abstract}

Results: 36 families and 53 children have participated in the project up to now. The results of the questionnaires have underlined the absence of psychopathological symptoms in children, the presence of more collaboration in the families and more possibilities in the family to have an open communication about the cancer. In addition, most of the parents reported a considerable satisfaction with the intervention.

Conclusion: Support for open communication in the family about cancer should be acknowledged as an important aspect of oncology care to reduce family stress.

\section{Key words:}

Cancer; Oncology; Communication; Children; Parent-child relationship; Family functioning; Family intervention

\section{Introduction}

A diagnosis of cancer has a deleterious impact not only on the patient but also on the structure and the functioning of the family unit [1]. For families with children there are additional burdens in adjusting to this threatening situation. Children's sense of security may be affected because the parent could die from cancer or because they can see the parent doesn't feel well. In this condition the parent can have many thoughts and fears connected to the illness and the routine of everyday life can be disturbed by treatment schedules and repeated hospital admissions and visits. So the parent can have more difficulties in giving so much attention to the children as in the past and the children's needs may go unfulfilled [2]. A lot of studies indicate, as a consequence, that children of parents with cancer are at increased risk of developing psychological problems such as anxiety and mood disorders, psychosomatic problems, worsening of scholastic performance and difficulties in maintaining concentration [3-6]. They can also develop more aggressive behaviors with other children or with parents and feelings of guilt and shame. But, as we have said before, it's just at this moment that parents can have more difficulties in recognizing their children's suffering, thus worsening the situation.

A lot of studies indicate that family functioning is more predictive for children's psychological adjustment than any disease-related parameter, such as duration, prognosis [7-9].

These results indicate that family intervention in some way can play a major role in the prevention of mental health problems in children of cancer patients. Some studies focused on the efficacy of an open communication with children about their parent's illness to reduce distress $[3,10]$. But, on the other hand, actually several studies showed that parents often may be reluctant to talk openly with children about cancer because they are afraid of frightening them and so they think that if they don't tell them anything about the illness they will protect 
Citation: Gallina F, Mazza U, Tagliabue L, Sala F, Ripamonti C, Jankovic M (2016) How to Explain the Parents Cancer to their Children: A Specific Intervention to Enhance Communication Inside the Family . Clinics Mother Child Health 13: 217. doi: $10.4172 / 2090-7214.1000217$

Page 2 of 5

their children. Also, in some cases, parents can't have the necessary knowledge about children's reactions to the information about their illness and so they can have difficulties in the identification of the best way of facing and managing them. Parents also may tend to underestimate their children's need for information so they may think that it is not necessary to explain the illness. When parents wish to explain the illness they may not do it because they may not know how to tell them about the illness. On the other hand, children may find it hard to talk openly with parents about their thoughts and feelings concerning cancer because they can think they will increase their distress and because they may not know how to carry on this communication $[3,11,12]$. So it's very important to help children and parents to communicate with one another about the illness.

\section{Aims}

The project aims to inform or to improve children's knowledge about their parent's cancer and to promote open communication inside the family about illness-related concerns and emotions. More specifically, clinicians try to give children some details on the disease and on the side effects of the parent's medical treatments. In addition, other aims are to understand children's thoughts and feelings about their parent's illness and to enhance parental competence.

\section{Methodology}

This intervention has been realized at San Gerardo Hospital to give children the communication about their parent's cancer. The project has started in November 2012 and it is dedicated to children whose parent has a cancer and to the whole family.

The main characteristic is the involvement not only of the psychologist but also of the pediatric hemato-oncologist so that clinicians can integrate their different abilities. The psychologist has a specific competence in emotional reactions and family dynamics while the pediatrician has competence in physical illnesses and therapies.

This intervention is also based on the direct involvement of children: there are specific sessions dedicated to the communication to children of the parent's diagnosis without the parents present. It is being realized in this way because children can feel freer to share their fears and to ask some questions that could frighten parents

The intervention is formed by the following steps:

1. Parents Sessions: The psychologist explains the project and assesses the family functioning with specific attention to resources, coping styles and parent's concerns. More specifically the way in which parents share illness-related information and fears with other close adults and with their children is explored. Parents are free to accept or refuse the intervention.

2. Sessions with Children: Without parent's presence, the pediatric hemato-oncologist and the psychologist describe, with the support of images and metaphors, the parent's cancer and its treatment. In particular to explain the illness the pediatric hemato-oncologist uses the "Flowered Garden" metaphor, in which he compares the body to a garden and the weeds to the illness that the treatments have to cut off. In addition clinicians explore on one hand the children's fears about the illness and their coping skills and on the other hand the way in which the children see themselves e their parents. The specialists explain the reasons for possible changes in parent's behavior and attitudes.

3. Family Sessions: In this phase the psychologist and the pediatric hemato-oncologist share with the parents the contents of the previous sessions.

These sessions are useful for the clinicians in order to observe the real family dynamics and for the families in order to facilitate the communication and the emotional sharing. In fact in this way they can have a first structured space to talk to one another.

4. Parents Counseling Sessions: The psychologist supports or improves the parent's competence and stimulates an open communication. The clinician helps parents to develop problem solving skills, to improve the affective involvement between family members and the parent's attention to children's emotional and concrete needs.

At the end of the intervention, if parents ask for more support or if clinicians detect severe psychopathological conditions in children, further family sessions and individual support for children can be structured.

\section{Study Measures and Analysis}

A specific ad hoc questionnaire for evaluation of the intervention was prepared with the collaboration of a university researcher and her team who have specific competences in realizing psychological researches and measurement designs. The self-reported questionnaire, given to the parents one month after the sessions with children, is characterized by items with multiple choice closed-ended questions. It investigates different topics: psychological symptoms in children, family's atmosphere (cohesiveness and communication intensity about the illness in the family), and satisfaction with the intervention.

\section{Results}

36 families and 53 children participated in the intervention: In most of the cases the ill parent was the mother. Most of them had breast cancer and were taking chemotherapy.

The children's average age is 8.95 and $58 \%$ of the children were males (Table1).

\begin{tabular}{|l|l|l|l|}
\hline Children's age & & $41-46$ yrs & 8 \\
\hline $4-7$ yrs & 25 & $>47$ yrs & 4 \\
\hline $8-11$ yrs & 12 & Patient's education & 10 \\
\hline $12-15$ yrs & 11 & Post graduate school/university & \\
\hline
\end{tabular}


Citation: Gallina F, Mazza U, Tagliabue L, Sala F, Ripamonti C, Jankovic M (2016) How to Explain the Parents Cancer to their Children: A Specific Intervention to Enhance Communication Inside the Family . Clinics Mother Child Health 13: 217. doi: $10.4172 / 2090-7214.1000217$

Page 3 of 5

\begin{tabular}{|l|l|l|l|}
\hline $16-18$ yrs & 5 & Secondary school & 20 \\
\hline Children's sex & & School left before 24 yrs & 6 \\
\hline Males & 31 & Patient's employment & 30 \\
\hline Females & 22 & Employed & 6 \\
\hline Family structure & & Not employed & \\
\hline Only child & 25 & Parent's diagnosis & 29 \\
\hline Two or more children & 11 & Breast cancer & 2 \\
\hline Single parent & 2 & Lung cancer & 1 \\
\hline III parent & & Gynecological cancer & 2 \\
\hline Mother & 32 & Colon cancer & 2 \\
\hline Father & 4 & Pancreas cancer & \\
\hline Patient's age & & Parent's Oncological treatment & \\
\hline $30-35$ yrs & 11 & Chemotherapy & 32 \\
\hline $36-40$ yrs & 13 & Radiotherapy & 4 \\
\hline
\end{tabular}

Table 1: Characteristic of the sample.

This table describes the characteristics of the sample; it includes demographic and medical characteristics.

Up to now the questionnaire has been administered to 50 parents and we have analyzed those items we think can be more representatives of the topic investigated, based on the studies reported in bibliography. Some questionnaires have not been administered because parents have died ( 3 mothers and 2 fathers) or families $(8$ families) were unavailable, because they live far away from the hospital.

Most of the parents did not report the presence of psychopathological conditions. In particular they described their children as never being more irritable (64\%), nor more anguished (74\%), nor did more depress (94\%). The majority of parents also did not detect a worsening of aggressive behaviors with them (74\%) nor with other children (94\%) nor a worsening of scholastic performance (82\%). In addition most parents did not report feelings of shame (84\%) or guilt (94\%) in their children.

As for the family atmosphere the majority of the parents after the intervention reported the sensation of feeling very much $(28 \%)$ or quite a lot $(50 \%)$ closer to one another, the presence of very much (22\%) and quite a lot (46\%) more collaboration and very much $(52 \%)$ and quite a lot (32\%) more possibilities to have an open communication about the cancer.

Also, most of the parents reported a considerable satisfaction with the intervention, both as regards the clinicians' explanation to the child (30\% rated it "very good", $70 \%$ "excellent") and the clinicians' way of relating to them (34\% rated it "very good", 64\% "excellent") and their children (34\% rated it "very good", 66\% "excellent") (Table 2).

\begin{tabular}{|l|l|l|l|l|l|}
\hline $\begin{array}{l}\text { Children's psychological conditions } \\
\text { after the intervention }\end{array}$ & Never & Rarely & Sometimes & Often & Always \\
\hline More irritable & $27(64 \%)$ & $4(8 \%)$ & $4(8 \%)$ & $5(10 \%)$ & $0(0 \%)$ \\
\hline More anguished & $37(74 \%)$ & $9(18 \%)$ & $2(4 \%)$ & $2(4 \%)$ & $0(0 \%)$ \\
\hline More depressed & $47(94 \%)$ & $3(6 \%)$ & $0(0 \%)$ & $0(0 \%)$ & $0(0 \%)$ \\
\hline More aggressive with parents & $37(74 \%)$ & $7(14 \%)$ & $4(8 \%)$ & $2(4 \%)$ & $0(0 \%)$ \\
\hline More aggressive with other children & $47(94 \%)$ & $3(6 \%)$ & $0(0 \%)$ & $0(0 \%)$ & $0(0 \%)$ \\
\hline Scholastic performance worsened & $41(82 \%)$ & $3(6 \%)$ & $5(10 \%)$ & $1(2 \%)$ & $0(0 \%)$ \\
\hline Blaming themselves for parent's cancer & $47(94 \%)$ & $3(6 \%)$ & $0(0 \%)$ & $0(0 \%)$ & $0(0 \%)$ \\
\hline Feeling ashamed for their parent's cancer & $42(84 \%)$ & $7(14 \%)$ & $1(2 \%)$ & $0(0 \%)$ & $0(0 \%)$ \\
\hline Family's atmosphere after the intervention & Not at all & Very Little & Moderately & Quite a lot & Very much \\
\hline
\end{tabular}


Citation: Gallina F, Mazza U, Tagliabue L, Sala F, Ripamonti C, Jankovic M (2016) How to Explain the Parents Cancer to their Children: A Specific Intervention to Enhance Communication Inside the Family . Clinics Mother Child Health 13: 217. doi: $10.4172 / 2090-7214.1000217$

Page 4 of 5

\begin{tabular}{|l|l|l|l|l|l|}
\hline Feeling closer to one another & $1(2 \%)$ & $0(0 \%)$ & $10(20 \%)$ & $25(50 \%)$ & $14(28 \%)$ \\
\hline More open communication about the parent's cancer & $1(2 \%)$ & $0(0 \%)$ & $7(14 \%)$ & $16(32 \%)$ & $26(52 \%)$ \\
\hline More collaboration & $3(6 \%)$ & $1(2 \%)$ & $12(24 \%)$ & $23(46 \%)$ & $11(22 \%)$ \\
\hline Satisfaction with the intervention & Poor & Fair & Good & Very Good & Excellent \\
\hline About the clinicians' explanation to the child & $0(0 \%)$ & $0(0 \%)$ & $0(0 \%)$ & $15(30 \%)$ & $35(70 \%)$ \\
\hline About the clinicians' way of relating to parents & $0(0 \%)$ & $0(0 \%)$ & $1(2 \%)$ & $17(34 \%)$ & $32(64 \%)$ \\
\hline About the clinicians' way of relating to children & $0(0 \%)$ & $0(0 \%)$ & $0(0 \%)$ & $17(34 \%)$ & $33(66 \%)$ \\
\hline
\end{tabular}

Table 2: Results of the questionnaires.

This table describes the results of the questionnaires given to parents after the intervention. The questionnaire investigates different topics: psychological symptoms in children after the intervention, family's atmosphere after the intervention and satisfaction with the intervention.

\section{Discussion}

Although all the participating families were united by the common denominator of having a relative diagnosed with cancer, they were very different in their unique dynamics, concerns and circumstances. Thus specialists found individual ways to talk with children and parents.

Parents were inexperienced and uncomfortable in having to deal with a cancer diagnosis and they had a pressing need for confirmation and reassurance. The evaluation, obtained by the questionnaires, underlined the parents' satisfaction with the intervention. Parents explained that after the intervention they felt closer to one another inside the family and they succeeded in facing cancer conditions with less difficulties because they did not have to mask the cancer treatments and their feelings. As a consequence they underlined that they had more possibilities to ask for and obtain help by their relatives. Gaining a clearer understanding of their children's reactions and feelings, parents underlined that they felt more confident with their parental roles and that they learned to talk to their children about illness-related topics with more naturalness and with less fear. These results have confirmed the previous studies that highlighted the importance of cohesion to facilitate effective family adaptation to a diagnosis of cancer.

One of the most important characteristic of this intervention is the enhancement of the children's role. They told their parents and clinicians that they were satisfied with their direct engagement, without parents present, with the specialists because in this way they felt they were an important part of the family system and they understood that in their families no lies were being told about the illness and so they could trust their parents. Some studies underline that communication and expressiveness in families can be identified as a key issue in children's positive coping with parental illness $[10,13]$. Our findings in fact underlined the absence of psychological problems in children after the intervention.

During the children sessions the most discussed topics were the side effects of the therapies and the fear of death. The explanations given to children by clinicians help them to avoid misleading assumptions that the absence of physical effects means "getting better" while increased physical symptoms implies a worsening of condition.
Some limitations of the study are linked to the small size of the sample, which limits further generalizations, and the use of selfreported questionnaire. Parents in fact may have failed to detect the specific problems in their children and they may have been influenced by social desirability bias. The absence of a pre-post intervention evaluation and the analysis of some items of the questionnaire only are additional limitations.

Identifying the most appropriate time point for initiating an intervention proved to be a crucial issue in the implementation of our service. We observed that cancer patients who were referred to our service too late after the initial diagnosis most commonly did not utilize it.

This intervention confirms the previous studies about the importance of an open communication to support children to face with cancer's diagnosis $[5,10,14-16]$. The project highlights the advantages of direct engagement of children in the communication of the parent's illness to improve the relationships within the family. In particular the intervention underlines the importance of respecting the children's dignity and of recognizing their role in the family. Clinicians try to offer heed and active attention to children's beliefs and emotions that parents have often difficulty in understanding. As a consequence, clinicians also help parents to increase their parental competence and to recognize the meaning of the nonverbal communication their children often use and which may not be immediately and clearly interpreted.

In addition the project underlines the importance of the integration of different competences, medical and psychological, to give a clearer and more complete communication.

Hospital clinicians can play an important role in guiding, supporting and giving information to patients with cancer but it is important to recognize the children's needs for information in order to help them to cope with the emotional strain of having an ill parent.

\section{References}

1. Kennedy VL, Lloyd-Williams M (2009) Information and communication when a parent has advanced cancer. J Affect Disord 114: 149-155.

2. Semple CJ, McCance T (2010) Parents' experience of cancer who have young children: a literature review. Cancer Nurs 33: 110-118.

3. Bugge KE, Helseth S, Darbyshire P (2009) Parents' experiences of a Family Support Program when a parent has incurable cancer. J Clin Nurs 18: $3480-3488$. 
Citation: Gallina F, Mazza U, Tagliabue L, Sala F, Ripamonti C, Jankovic M (2016) How to Explain the Parents Cancer to their Children: A Specific Intervention to Enhance Communication Inside the Family . Clinics Mother Child Health 13: 217. doi: $10.4172 / 2090-7214.1000217$

Page 5 of 5

4. Lindqvist B, Schmitt F, Santalahti P, Romer G, Piha J (2007) Factors associated with the mental health of adolescents when a parent has cancer. Scand J Psychol 48: 345-351.

5. Kennedy VL, Lloyd-Williams M (2009) How children cope when a parent has advanced cancer. Psychooncology 18: 886-892.

6. Huizinga GA, van der Graaf WT, Visser A, Dijkstra JS, Hoekstra-Weebers JE (2003) Psychosocial consequences for children of a parent with cancer: a pilot study. Cancer Nurs 26: 195-202.

7. Osborn $\mathrm{T}$ (2007) The psychosocial impact of parental cancer on children and adolescents: a systematic review. Psychooncology 16: 101-126.

8. Lewis FM, Casey SM, Brandt PA, Shands ME, Zahlis EH (2006) The enhancing connections program: pilot study of a cognitive-behavioral intervention for mothers and children affected by breast cancer. Psychooncology 15: 486-497.

9. Zahlis EH (2001) The child's worries about the mother's breast cancer: sources of distress in school-age children. Oncol Nurs Forum 28: 1019-1025.

10. Romer G, Saha R, Haagen M, Pott M, Baldus C, et al. (2007) Lessons learned in the implementation of an innovative consultation and liaison service for children of cancer patients in various hospital settings. Psychooncology 16: 138-148.

11. Buxbaum L, Brant JM (2001) When a parent dies from cancer. Clin J Oncol Nurs 5: 135-140.

12. Helseth S, Ulfsaet N (2005) Parenting experiences during cancer. J Adv Nurs 52: 38-46.

13. Forrest G, Plumb C, Ziebland S, Stein A (2009) Breast cancer in young families: a qualitative interview study of fathers and their role and communication with their children following the diagnosis of maternal breast cancer. Psychooncology 18: 96-103.

14. Edwards L, Watson M, St James-Roberts I, Ashley S, Tilney C, et al. (2008) Adolescent's stress responses and psychological functioning when a parent has early breast cancer. Psychooncology 17: 1039-1047.

15. Niemelä M, Hakko H, Räsänen S (2010) A systematic narrative review of the studies on structured child-centred interventions for families with a parent with cancer. Psychooncology 19: 451-461.

16. Rauch PK, Muriel AC (2004) The importance of parenting concerns among patients with cancer. Crit Rev Oncol Hematol 49: 37-42. 